\title{
2 Different views on scholarly talent: What are the talents we are looking for in science? ${ }^{1}$
}

\begin{abstract}
In this paper we study the evaluation of talented early career researchers, as done in grant allocation processes. To better understand funding decisions, we studied the grant allocation process in more detail, and compare the notion of talent in grant allocation with more general notions of talent existing in the academic work environment. The comparison is based on interviews with 29 scholars who have experience with identifying talent both in their daily academic work and in the process of grant allocation. Overall there is large agreement on the notion of talent. However, the characteristics ascribed to top talent vary depending on the evaluation context. In grant allocation a narrower talent definition prevails compared to more general evaluation. Furthermore, difficulties arise in the process of panel decision-making, when selection criteria need to be concrete and explicit to enable comparison. Having to choose between many applicants of similar quality makes the selection process liable to subjectivity, arbitrariness and randomness. Despite these uncertainties, grants are ascribed a very high symbolic value. Small quality differences are enlarged into considerable differences in recognition, consequently affecting career opportunities, as they provide academics with both financial and symbolic resources.
\end{abstract}

\subsection{Introduction}

The quality of higher education and research is strongly connected to the quality of the people working in the academic sector. For excellent science, excellent scientists are needed. Therefore government and universities specifically aim at selecting the best people when investing public resources in education and research. This has led to an increased focus on talent and talent policy, especially within the group of early career researchers. This is a general phenomenon, also clearly visible within the Netherlands, the specific context of this study. In the hiring policies of Dutch universities the notion of talent nowadays has taken a central position. It is becoming a key issue in Higher Education for Human Resource Management (HRM); a management tool that focuses on individual performance (Waring, 2013). Several programs and policy initiatives are currently implemented to attract and stimulate academic talent, e.g. the Tenure Track program, scholarships for excellent PhD students, and mentoring programs for promising female academics (De Boer \& Jongbloed, 2010; Van den Brink, Fruytier \& Thunnissen, 2012). Furthermore, many programs are directed towards motivating researchers to apply for external grants and to increase the chances of young researchers to acquire external funding. They involve pre-selection processes, encouragement by dedicated mentors, training and supervision of writing grant applications, and improvement of presentation skills (Neufeld, Huber and Wegner, 2013).

The increased focus on acquiring external funding is both a deliberate consequence of changes in funding policy (from institutional towards project funding), as it is a result of the growing pool

1 This chapter has been accepted for publication by Research Evaluation as Van Arensbergen, P., Van der Weijden, I. \& Van den Besselaar, P. (forthcoming). Different views on scholarly talent: What are the talents we are looking for in science? 
of competent scholars with academic career ambitions. Government funding used to be predominantly allocated as block funding to the entire university or research institute. Nowadays, in many countries intermediaries like research councils have taken an important position in the distribution of resources, as they allocate an increasing share of government funding directly to individual researchers or research groups (Lepori et al., 2007). Securing external research grants has become a prominent criteria in academic recruitment, evaluation and promotion processes in science (Bloch, Graversen \& Pedersen, 2014; De Jonge Akademie, 2010; Laudel \& Gläser, 2012; Van Arensbergen, Hessels \& Van der Meulen, 2013). Therefore, career opportunities as well as university appointment decisions of individual scientists depend on granting decisions made by external funders, like the European Research Council (ERC) or the Dutch Research Council (NWO). Personal career grants are to an increasing extent considered as a necessary resource in order to further develop an academic career. The real effect of these grants on someone's career is subject of many studies. A recent study (Laudel \& Gläser, 2012) on the impact of ERC grants on careers of grantees, showed that several organizations responded to the reputation of ERC grants by promoting (mainly ERC starting) grantees or by offering them tenure. At the same time the grants were found to only play a minor role in promoting inter-organizational mobility. Most of the grantees already worked in the best possible environments, and/or were settled with their families which constrained them to move. A Danish study showed that grant recipients from the Danish council for Independent Research have a higher probability of becoming a full professor (16\%) compared to rejected applicants (9\%). Also grant recipients stressed the central role of grants in facilitating subsequent collaboration with leading researchers in their field and in establishing their own positions in research communities (Bloch et al., 2014).

A successful personal funding instrument of the Dutch Research Council is the Innovational Research Incentives Scheme (Vernieuwingsimpuls). Gerritsen, Plug and Van der Wiel (2013) recently studied the effect of these grants and found that they indeed increase one's chance of a successful academic career. Comparing applicants with about the same priority scores, they found that grantees are more likely than rejected applicants to stay in academia, receive followup grants and become a full professor. These results show that the allocation of personal career grants is an important context of talent selection. To study the notion of talent within science, the process of grant allocation is therefore included and investigated in more detail.

\subsection{Research questions}

In this study we investigate the process of talent selection in more detail with a twofold aim. On the one hand we want to create a better understanding of the notion of academic talent. What are the talents the academic community is looking for, both within academia in general as within grant allocation procedures? On the other hand we want to open up the black box of grant allocation by scientific panels. For improving the transparency, quality and legitimacy of grant allocation practices, it would therefore be important to uncover the details of the de facto (implicit and explicit) applied criteria. Which characteristics of applicants do panel reviewers value the most and how do they reach agreement within panels?

\subsection{Theoretical background}

The word 'talent' clearly has a positive connotation, but there is no general consensus on the exact meaning of it. A highly debated issue, for example, is the origin of talent: is talent innate or 
acquired (e.g. Baron-Cohen, 1998; versus Howe, Davidson \& Sloboda, 1998)? A recent quantitative study on career grant allocation showed that except for a few positive outliers (top talents), no evident pool of talents could be identified based on review scores (Van den Besselaar \& Van Arensbergen, 2013). Thomas and Nedeva (2013) recently developed a multidimensional framework of 23 elements to characterize talented researchers, based on an extensive literature review. Examples of these elements are geographic and workplace mobility, demographic variables and the amount of academic service tasks undertaken.

\subsubsection{Symbolic capital}

In this paper we relate the notion of talent to 'symbolic capital' (Bourdieu 1986). Bourdieu discerned several forms of capital, most importantly economic (financial resources), cultural (education and upbringing) and social (relations and networks) capital. In every field, like politics, arts, economy and science, there is competition for accumulating as much capital as possible. The general distribution of these types of capital and the way they can be accumulated is field specific. The various forms of capital can be converted into other forms, most importantly into symbolic capital. Symbolic capital concerns the reputation and prestige accredited to someone, based on the recognition of his accumulated capital. In science this is mainly determined by the judgment of peers. Evaluation processes - whether it concerns reviewing scientific manuscripts for publication or assessing academics for recruitment or promotion practices - can be charac-terized as selfgoverning as they are mainly executed by academics themselves. Academic reputation and quality therefore lives by peer recognition. We relate symbolic capital to talent selection, since assigning the prestigious label of talent can be seen as recognition of a person's accumulated capital.

What is considered to be valuable capital and how it can be accumulated, is determined by the academic habitus. According to Bourdieu's concept of habitus, academics generally have internalized certain dispositions and norms in response to objective conditions they encountered through their academic work. The habitus is shaped by past experiences and guides current behavior and thinking within a specific field. It refers to the embodiment of certain dispositions, so not only at the explicit conscious level (Bourdieu, 1988). From the perspective of talent selection, habitus determines what is considered to be valuable capital, as it relates to dispositions academics should have or should develop in time. People are not only assessed on their current dispositions, but also on their potential, what are they expected to become, reflecting the habitus of the more established academics. Looking into how academics decide who is talented and who is not, will provide more insight in which qualities of academics the scientific community value the most and are part of the academic habitus.

In this study we modify Bourdieu's forms of capital and differentiate between professional, individual and social capital, following the example of Van den Brink (2009), who applied the concept of symbolic capital to appointment practices within academia. Professional capital involves skills, experience and achievements related to research, teaching and management. This is mainly assessed from track records, e.g. in terms of years of experience, former employers, number of publications and acquired funding. Formal assessment criteria predominantly reflect professional capital. Individual capital has more of a subjective character and is about personal traits and motivation. For example creativity, perseverance, commitment and likeability relate to individual capital. Finally, social capital is defined as consisting "of an aggregation of networks 
and these networks provide access to certain resources and positions of power" (Van den Brink, 2009: p. 145). Social capital is not only valuable as it itself can be converted into symbolic capital, it also serves as an accelerator for turning accumulated professional and individual capital into symbolic capital: academic prestige. As science is turning more into a social activity, and as collaboration is of growing importance, we chose to extend the concept of social capital with those skills and traits needed for interaction and collaboration - the skills needed for creating and maintaining social networks. Thus, some of the skills that generally are considered as professional or individual capital, (e.g. communication skills, ability to collaborate, and social attitudes), are treated in this study as (conditions for) social capital.

To summarize, in this paper we study symbolic capital in the context of talent selection, as the recognition of professional, individual and social capital. We will identify the skills and traits characterizing talent and categorize them as one of the three types of capital (see table 3).

\subsubsection{Academic talent selection}

An inventory of definitions of talent in policy documents of several Dutch universities (Thunnissen, Fruytier \& Van den Brink, 2010), shows that the general descriptions of talent leave considerable room for interpretation: talents are people who perform better than expected based on their age and/or experience (p. 20), or talents are they of whom is expected to be able to shortly acquire a position as an associate professor (p. 19). The main criteria for assessing young talents are publications, study and promotion results, honors degrees, awards, grants, and international experience. These criteria primarily relate to professional capital. To a lesser extent individual capital is mentioned within policy documents, such as motivation and drive.

Evaluation of scientific quality is often carried out in panels. To understand how talent is evaluated and selected in these panels, it is not enough to only study characteristics of the talents and the reviewers. Panel decisions are influenced by, and the result of, group interaction, making group and context characteristics important variables to include. Luukkonen (2012) studied review processes of ERC panels and showed how panel decisions are steered by customary interpretative and deliberation rules. From literature reviews on this type of panel reviewing, we learn that, for example group composition, group dynamics (e.g. discussion, sharing of information, power relations), characteristics of the procedure and contextual factors (e.g. budget, time pressure, accountability) can strongly affect the decision outcomes (Olbrecht \& Bornmann, 2010; Van Arensbergen, Van der Weijden \& Van den Besselaar, forthcoming). These factors impede the transparency and predictability of decision-making processes. However, as this type of panel evaluation involves interactions between human beings, it needs to be considered as a social and emotional process. Therefore, it is impossible to completely rule out any form of subjectivity (Lamont, 2009).

In this paper, we approach the process of talent selection as a strongly subjective process. We study it as fully as possible by investigating the decision-making process on both the individual and group level. We look at how reviewers use formal procedures and interpret formal criteria in their own way when evaluating grant applications. Furthermore, we analyze panel discussions and the way panels reach their final allocation decisions. By studying the process of personal grant allocation, we aim to get a better understanding of how symbolic capital is ascribed within academic talent selection. 


\subsection{Data and methods}

Data for this article consists out of 29 semi-structured interviews with members of grant panels. All the respondents were involved in reviewing and allocating personal career grants in 2009 for two funding programs within the Talent Program called Innovational Research Incentives Scheme (Vernieuwingsimpuls) of the Dutch Research Council (NWO). Table 1 gives an overview of these funding programs, the Early Career Grant (ECG) and Intermediate Career Grant (ICG) scheme. This grant scheme is not limited to a certain scientific domain, but has eight domain panels and one interdisciplinary panel. In this paper we grouped the eight domains into two main domains: Social Sciences and Humanities (SSH), and Natural and Technical Sciences (NTS).

Table 1 Innovational Research Incentives Scheme

\begin{tabular}{|c|c|c|c|}
\hline & & Early career grant (Veni) & Intermediate career grant (Vidi) \\
\hline \multicolumn{2}{|l|}{ Career conditions } & $0-3$ years after $\mathrm{PhD}$ & $0-8$ years after $\mathrm{PhD}$ \\
\hline \multicolumn{2}{|l|}{ Funding } & Max. $€ 250.000$ per grant & Max. $€ 800.000$ per grant \\
\hline \multicolumn{2}{|l|}{ Duration } & 3 years & 5 years \\
\hline \multicolumn{2}{|l|}{ Number of grants } & 150 per year & 85 per year \\
\hline \multirow[t]{5}{*}{ Acceptance rates (\%) } & 2002 & 25 & 17 \\
\hline & 2005 & 22 & 26 \\
\hline & 2008 & 18 & 21 \\
\hline & 2012 & 16 & 14 \\
\hline & 2013 & 15 & 20 \\
\hline
\end{tabular}

From the list of about 220 panellists active in 2009, we invited 40 of them across the various domains for an interview. Efforts were made to attain comparable numbers of women and men. The large majority was willing to participate: five people did not reply and seven were willing but unable to participate due to time constraints or illness. The respondents are predominantly associate or full professor and come from various scientific domains, from social sciences to life sciences (see table 2 for more details). Most of the respondents have been involved in this type of grant allocation for several years, have experience in internal selection processes at the university, and have been active as (national and international) peer reviewers.

Table 2 Overview of the respondents per program, domain and gender

\begin{tabular}{l|c|c|c|c|c}
\hline & \multicolumn{2}{|c|}{ ECG } & \multicolumn{2}{c}{ ICG } & Total \\
\hline & Male & Female & Male & Female & 14 \\
\hline Social Sciences \& Humanities & 4 & 5 & 2 & 3 & 14 \\
\hline Natural \& Technical sciences & 7 & 3 & 2 & 2 & $29^{\star}$ \\
\hline Total & 11 & 8 & $5^{\star}$ & 5 & \\
\hline
\end{tabular}


The research fieldwork was conducted in the beginning of 2012. Most of the interviews were conducted at the respondent's workplace (27), two were done by telephone, with an average duration of one hour. Respondents were asked about identification of talent in their daily academic work (e.g. describe young academics that clearly stood out in their group or who they really would have liked to retain). As this type of identification concerns the respondent's general view on talent apart from any specific selection or appraisal procedures, we refer to this as general talent identification. We feel this provides a useful frame of reference to better understand specific types of talent selection. Then we asked about talent selection within the grant panel (e.g. how do they review the grant applications; what criteria do they use in the different phases of the selection process; how do they recognize the top talents; how are the applicants discussed within the panel; how does the panel reach the final allocation decisions?). This we will call concrete grant talent selection, because of the presence of concrete selection procedures and because actual selection takes place.

All interviews were audiotape recorded, transcribed verbatim, send back to interviewees for authorization and coded using the software program Atlas.ti (see table 3 for summary of this code scheme).

Table 3 Most important codes describing the three types of capital

\begin{tabular}{l|l|l}
\hline \multicolumn{1}{c|}{ Professional } & \multicolumn{1}{c}{ Individual } & Social \\
\hline Awards & Ability to work hard & Ability to motivate others \\
\hline Broad expertise & Ability to work independently & Being proactive \\
\hline Clear presentation (interview) & Ambition & Being social \\
\hline Comprehensible proposal & Authenticity & Communication skills \\
\hline Cum laudes & Enthusiasm & Fit in a group \\
\hline Elaborate proposal & Goal directed & Having a large network \\
\hline Grants & Leadership skills & Persuasiveness \\
\hline International experience & Originality & Social skills \\
\hline Previous employers/institutes & Perseverance & Team spirit \\
\hline Publication record & Self-consciousness & \\
\hline Writing skills & Willingness to learn &
\end{tabular}

\subsection{Results}

First we focus on how talent is generally identified in daily work at the university, before shifting to talent selection in the concrete context of grant allocation. At the end of this paper we will look into the process of group decision making and which difficulties panellists face in the final phase of the selection process. As our main focus is not on gender, career stage or disciplinary differences, we will not structurally compare men and women, nor the ECG and ICG schemes, nor the NTS and SSH domains when describing our results, but only where we found important differences. 


\subsubsection{The general concept of scholarly talent}

Real talents were said to be easily and widely recognized. They are those who do not excel on one single dimension, but on various dimensions, combining all forms of capital. Talent is multidimensional. Related to professional capital talented academics distinguish themselves from others by having broad expertise, excellent writing skills and above all a high productivity. Productivity is positively assessed when one has a high number of publications, also first authored, preferably in prestigious journals with a high impact factor. This is in line with the formal criteria formulated in many career policy documents.

Although young academics need to have accumulated considerable professional capital to be identified as talent, respondents emphasized talents above all stand out from the majority because of their individual capital. Especially female respondents strongly value this type of capital as more than half of all traits mentioned by women had to do with personality and motivation. The personality trait that is central to the academic habitus and mentioned most frequently - by both men and women - is the ability to work very hard. People who lack this ability will never make it in science, especially in top science. This also means young researchers need to be very ambitious and eager, possess a strong drive to become a top researcher, and work with great enthusiasm and passion. Since the academic world is a competitive world and setbacks are unavoidable, perseverance is considered to be an exigency, a crucial part of the academic habitus. Top talents do not let themselves be demotivated by rejections and negative reviews, but they learn from them and use these experiences to grow. Furthermore, talents are willing to learn, and are strongly self-conscious and goal directed. A last personal trait, which seems to be more important within NTS compared to SSH, is the ability to work independently and 'think for yourself'.

Being a social person is found to be a primary requirement in order to be considered a talent. As science is not purely an individual activity, but becomes to an increasing extent a social activity, it is found of great importance to fit well in a group and to have good social skills. Social skills seem to become a more important part of the academic habitus over time. In line with Bourdieu's meaning of social capital, young talents are described as people who already created their own significant network and are not just embedded in their professor's network. ${ }^{2}$ Having a strong network is seen as meaningful in two ways. It shows they are good academics, as they are acknowledged by other people who they are connected with. But it is also considered a strategy in order to increase your career opportunities and academic success. If you really want to be successful in science you need to have the right connections and the ability to make and maintain these connections. Interestingly, having your own network as characteristic of talent was only mentioned by women, not by men. This could be explained by earlier research (Bleijenbergh, Benschop \& Vennix, 2013; Van den Brink, 2009) suggesting that networks play an important role in distribution of information, resources and career opportunities. As men are overrepresented in academia and have more homogenous networks than women (Brass, Joseph, Greve et al., 2004), women may be disadvantaged and therefore more aware of the importance of having a good network. 
Other social characteristics valued in talents are having a strong team spirit, being interested in others, willing to help others and being able to motivate them. Finally, talents have good communication skills, take a lot of initiative and they are proactive.

"On the one hand you want to hire the best people, but they should also fit in the group. Some people are very good, but completely antisocial. [...] we are all just human beings and we want someone in our group who is a nice person. There are plenty of people with whom in theory I could collaborate with perfectly content wise. But the chemistry is not right or there are little things of which you think, am I going to invest my time in this?" (male, interdisciplinary)

To sum up, the majority of characteristics of talent valued in general daily academic work can be described as features of individual capital: personal traits, motivation and ambition. For women this holds even stronger than for men.

However, one type of professional capital was found to be of special importance: acquired grants. A large majority of the respondents do not consider these simply as part of track records, but as a significant indicator in itself of previous recognition of talent. In times of severe competition and generally low allocation rates, grants have an important value. They provide the receiver with both financial resources and prestige. Especially personal career grants as the ERC grants and the Dutch Veni- and Vidi-grants are considered very meaningful for young researchers.

"Currently it is extremely important to enter the Veni- and Vidi- trajectory or something similar at a very early stage. From the beginning of your career you should have received some sort of mark indicating you are on the right track. Those will get a plus for sure, they successfully passed the procedure. And the selections are very heavy, everyone knows. There you don't have a $80 \%$ chance, but more likely the opposite of 10 to $20 \%$. So if you have survived, it gives you the mark 'top', meaning you are obviously very good." (male, NTS)

As the selection is tough, those who managed to receive a grant are assumed to be excellent researchers. In the sociology of science this phenomenon is also known as the Matthew effect. Scientific credits like awards and grants are more often allocated to researchers who received them before, than to those who haven't, even when the quality of their work is similar (Merton, 1968). In terms of conversion of professional capital (grants) into symbolic capital (prestige), grants have a very high exchange rate. As these personal career grants are seen as important indicators of talent - also within career policy - we will in the next section take a closer look at this process of grant allocation.

\subsubsection{The concrete concept of talent within grant allocation}

The process of grant allocation within the Innovational Research Incentives Scheme (Vernieuwingsimpuls) consists of several evaluation phases. 3 The criteria used to evaluate the applications are found to vary across the several evaluation phases. For this reason we successively describe the various phases and which criteria are primarily used by individual reviewers in 
each phase. After subsequently comparing this concrete case to the just described general identification of talent on the individual level, we will describe how talent is deliberated within panels and how panels reach agreement with regard to talent selection.

\section{Pre-selection: many applications, limited information}

In case of a much higher number of applications compared to number of grants, the allocation procedure involves pre-selection, as often occurs. For the pre-selection panellists receive the research proposals and the curriculum vitae of the applicants. Applications are not yet sent to external reviewers, who can be considered to be the experts in the specific research area. Panels are composed in such a way that their members cover a broad expertise. This implies that the panel as a whole is assumed to have the expertise to review all proposals as good as possible. At the same time this implies that a single panellist lacks knowledge to accurately review all proposals. Respondents indicate to be aware of this and many of them consider the broadness of the set of applications as problematic and impeding the selection process. Especially taking into account that the rejection rate in this phase is often about forty percent.

Figure 1 Schematic overview selection procedure Innovational Research Incentives Scheme (Veni/Vidi)

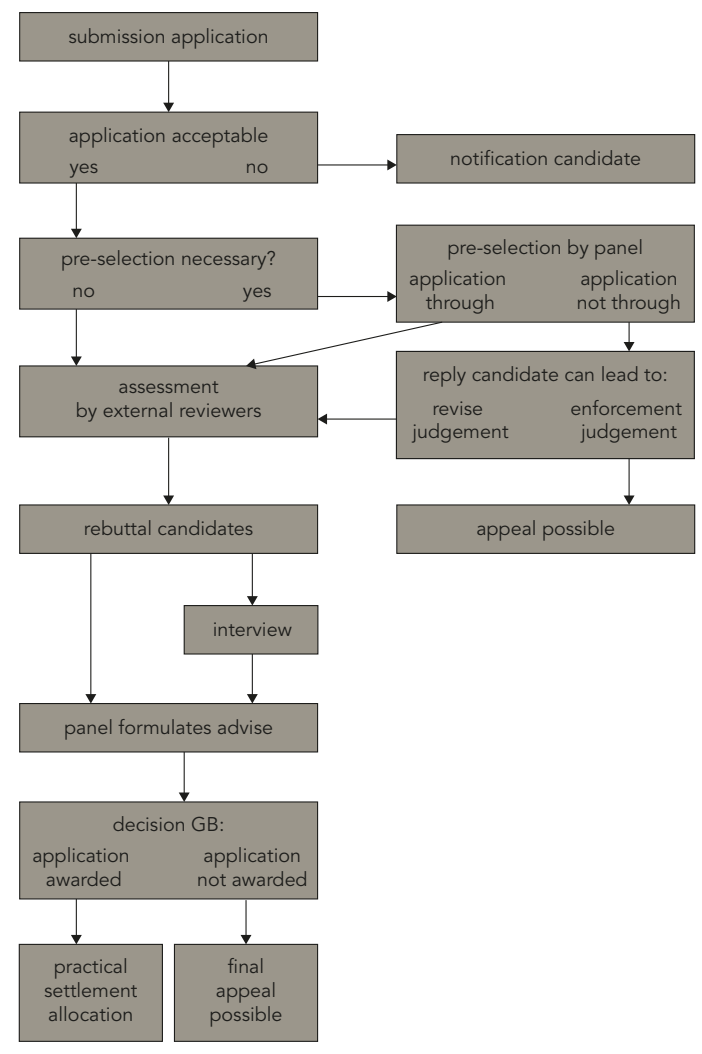




\begin{abstract}
"You need to review and judge research and performance of people from a completely different research field. And within the social sciences these differences are really huge. Certainly last time, we had people from psychology to law and so on. And yes, the tradition of publishing and way of working, everything is so different that you really are comparing apples and oranges. [...] At the same time it is an enrichment as you are confronted with things you consider to be normal while others don't, and the other way around. But it is quite difficult." (female, SSH)
\end{abstract}

Because of the heavy workload and the wide range of topics, panellists tend to primarily focus on the curriculum vitae of the applicant. The curriculum vitae, proof of mainly professional capital, is found to be generally easy to review for all applicants, regardless of disciplinary proximity.

"The applicant can be evaluated rather objectively. You can put a list next to it and count like, how many publications, how many awards, grants, honor degrees, that kind of things." (female, SSH)

List of publications is mentioned as the most important indicator of talent in this first selection phase. Secondly, especially according to female respondents, there should be a notification of international experience. More generally, respondents use the institute, lab or organization itself an applicant previously worked at as a quality criteria. However, this only holds for the NTS domain, as in the SSH domain it was only mentioned once. Similar to what we found with regard to general talent selection, honor degrees, awards and grants are highly valued as professional capital.

In this first evaluation phase the emphasis is on professional capital, as three quarters of all criteria mentioned are related to this type of capital. To a much smaller extent panellists review individual and social capital. These types of capital are found harder to assess based on résumé's and written proposals. Nonetheless panellists do look for indications of authenticity, independence, and leadership skills (individual capital) and for quality of the applicant's network (social capital). They mainly ground their assessment on (co-)authorship patterns. People are positively evaluated when they published without their promoter, with various researchers from other (international) institutes, and on topics different from their PhD research. They are seen as having clear goals and ideas about what they personally want to accomplish, as being able to create their own niche and network (authenticity), and to work independently.

Although the applicant's résumé is found to be most decisive, abstracts of research proposals are important too. All panellists, regardless of specific expertise, should be able to generally understand the abstract. If it is too specific or too much jargon is used, it will not be evaluated positively. Applicants are expected to be able to inform a broad audience about their research ideas.

"When I started, I remember in the first round I returned five or so of the thirty applications I had to review. I said I was not able to assess them. They were far out of my working range. In the second year, you don't do that anymore, as for the third year. Then you may think, oh no, not another one you don't understand. But after all, it is up to the applicants to make clear to everyone who reads the abstract what they aim to do. If they succeed it is fine, it is a good application. If they fail, it is not a good application." (female, NTS) 
In short, in the pre-selection phase the emphasis clearly is on professional capital as assessed from résumés. Besides having an impressive publication list, including first author publications, independent from the promoter and on a different topic, talents are able to communicate their research ideas in a clear and generally comprehensive way.

\section{Involving external peer review: bringing in more expertise}

Next, panels have to select applicants for the interview round. Proposals are reviewed more thoroughly beyond résumé and abstract. At first proposals are more globally assessed, and panellists determine their level of expertise regarding the specific topic. When one concludes to have enough expertise, (s)he will critically review the proposal in more detail. Otherwise, (s)he will leave the thorough evaluation of the actual content of the proposal up to external reviewers, who are the experts in the specific research area.

In this phase of the process applications are sent to (generally two or three) external reviewers based on their specific expertise. In an earlier quantitative study on grant allocation within the same Dutch research council and funding program, the external reviews were found to play a modest role in the selection process, which are eventually decisive (Van Arensbergen \& Van den Besselaar, 2012). This can be explained because panellists indicated to not automatically take over these expert reviews, but evaluate and weigh them. They primarily want to understand how the external reviewers determined their score. When external reviews lack a clear motivation or when panellists disagree, they can decide not to take it into account when formulating their own score.

"Some external reviews are very good, some are very bad. It is also possible to put the external reviewer offside, I agree. We had several situations in which we thought that the review did not come up completely objectively. This person is only trying to slice down the applicant instead of giving serious feedback. You also check if your opinion on the applications matches the opinion of the external reviewers." (female, SSH)

When panellists evaluate the quality of the research proposal the focus is predominantly on elaboration. It should contain a complete description of the research idea, context, methodology, relevance etc. No gaps or any missing information. As in the pre-selection, generally understandable phrasing is strongly valued. Other important criteria are originality and innovativeness of research topics, and feasibility of proposals. However, some proposals describe very innovative research questions, but lack any clear evidence that the applicant will be able to answer them (in time). These proposals score lower. Furthermore panellists want to be convinced that the proposal is really the applicant's work. It should be part (or the beginning) of their own line of research, not of their PhD supervisor. Just as in the pre-selection phase, authenticity is highly valued, showing their personal contribution to the proposal, and giving it their own clear signature.

To summarize, in this phase the emphasis is still on professional capital, as the most important criteria used by panellists are track record and a clearly elaborated and feasible grant proposal. Elements of individual capital are also assessed to some extent. Talents are those applicants who are creative, innovative, and most of all authentic. 


\section{Selection after the interview: having been face to face with applicants}

In the next stage a selection of applicants is reviewed in a face-to-face interview of about thirty minutes. Applicants present their proposal and answer questions of panellists. In line with earlier research, panellists indicate this is a very decisive phase in the selection process (see also Van Arensbergen \& Van den Besselaar, 2012). For some applicants it is a clear turning point, meaning a considerable shift in their ranking.

"I noticed that even if you received excellent external reviews, it can still go wrong completely. That is the most important role of the panel, you assume that if one has real talent, it will show in an interview of twenty minutes. You ask a few questions and then one has to think flexibly enough to respond with 'yes indeed, when this won't work out I still have this or that theory'. So it has to be someone who thinks about research in a realistic and flexible way and does not only have excellent papers. You notice rather quickly in interviews who you really consider to be a talent, not only on paper but as a real person." (female, NTS)

First of all talents are able to give a clear presentation, with a right balance of showing academic expertise and using a generally understandable language at the same time. Comments from the external reviewers given to them in the previous selection round, need to be taken up or contested with a clear explanation. Furthermore, the way in which applicants answer the questions is strongly assessed. For panels, this serves as an opportunity to test several of the criteria applied previously to the written application, predominantly authenticity. Where they can have received strong support from e.g. their promoter while writing the proposal, reflecting on the proposal they fully have to do themselves during the interview. This gives panels more room to assess individual capital and their academic habitus, as applicants' answers better reflect personal skills and ideas.

"Persuasiveness and enthusiasm, but also if you don't have that, enthusiasm needs to be there [during the interview], otherwise you're out. An extra check whether the person clearly comprehends [the topic] and whether it is really his own thing and the proposal is not written by someone else. You try to figure out if the person really is into it. As for content not much happens anymore, that happened beforehand. [...] I believe it are these things. They are often hard to prove, they are intuitive." (male, NTS)

As this male respondent indicates, during the interview intuition comes into play. Writing and presenting a proposal can be improved by training, and panels can evaluate them with a certain extent of objectivity. However, especially in this phase of the evaluation process, more subjective criteria related to individual capital play an important role, mainly enthusiasm, perseverance and ambition. Because it is all about allocating personal career grants, panellists want to be convinced that applicants really want to and are able to conduct the research project. Enthusiasm needs to be accompanied by strong persuasiveness. As this has to do with communication skills, this is linked to social capital. Finally panellists look at personality of applicants. Since there are only a few grants to allocate, they prefer allocating grants to someone they like instead of someone who appears arrogant or unfriendly. 
To summarize, also in this evaluation phase, the emphasis is on professional capital. Academic skills evaluated earlier in the procedure, are tested during the interview. Does the applicant really have the knowledge and skills to conduct the proposed research project? Furthermore, during the interview much more attention is paid to individual, and to a smaller extent also to social capital. Face to face contact enables panels to evaluate the real person behind the proposal. Talents are those who succeed in convincing the panel of their authenticity, enthusiasm, ambition, perseverance, and excellent communication skills. We found that for male panellists the shift in focus during the interview from professional towards individual capital is larger than for females. The same holds true for the NTS domain compared to the SSH domain.

\subsubsection{Tension between general and concrete talent identification}

After asking the respondents how they assess applicants and applications in each phase of the review process, we also asked them to describe the top talents they came across during their grant panel work. In table 4 we listed the ten characteristics that were mentioned most often by the respondents both in general (first part of study) and concrete assessments (in grant panels), with the most frequently named traits at the top.

Table 4 Top ten characteristics of talent in general and concrete talent evaluation ${ }^{a}$

\begin{tabular}{l|l}
\hline \multicolumn{1}{c|}{ General evaluation } & \multicolumn{1}{c}{ Concrete grant evaluation } \\
\hline Being social $(\mathrm{sc})^{\mathrm{b}}$ & Publication record (pc) \\
\hline Acquired grants as previous recognition $(\mathrm{pc})^{\mathrm{c}}$ & Elaboration research proposal (pc) \\
\hline Ability to work hard (ic) & General comprehensiveness (pc) \\
\hline Ambition (ic) & Authenticity (ic) \\
Publication record (pc) & Enthusiasm (ic) \\
\hline Ability to work independently (ic) & Originality (ic) \\
$\begin{array}{l}\text { Enthusiasm (ic) } \\
\text { Perseverance (ic) } \\
\text { Writing skills (pc) }\end{array}$ & Self-consciousness (ic) \\
\hline Being proactive (sc) & Ambition (ic) \\
\hline
\end{tabular}

a Characteristics within the same cell were mentioned just as often by the respondents and are therefore ordered alphabetically.

b $\mathrm{sc}=$ social capital, $\mathrm{pc}=$ professional capital, ic $=$ individual capital.

c Although grants can be considered professional capital, respondents referred to them more directly as symbolic capital: previous acknowledgement of prestige.

The main difference between the lists of traits is the variation in types of capital that are valued in talents. Within the top ten of general evaluation all three types of capital are represented, with number of acquired grants being a very important indicator for talent. In concrete grant evaluation the emphasis is on professional capital, complemented with several types of individual capital but no social capital. 


\subsubsection{Deliberating talent within panels}

Next, we will examine the decision-making process at the group level. How is talent discussed within panels and what eventually decides who receives formal recognition as being a talent? Both before and after the interview panellists meet to discuss their evaluations and come to a final priority ranking. During these meetings each proposal is generally introduced and commented upon by one or two panellists who were instructed to prepare a more extensive review. After this other panellists have the opportunity to respond, give their opinion or ask questions.

Panel discussions offer panellists the opportunity to explain criteria specific to their discipline, e.g. publication practices or research methods. As mentioned before, many panellists conceive the broad scope of the total set of applications in terms of topics and research fields as problematic. By exchanging information with the panellists who are experts on the specific proposal, panel meetings enable them to adjust their evaluation accordingly. The same holds true for evaluating the innovativeness, feasibility and relevance of proposals. In order to accurately assess these elements, one needs to be informed of the current state of the art of the related research field.

"You know the journals from the field you publish in yourself. You know the status and reputation of those journals and maybe of a few from outside your field, but of many journals you don't know this. We had interesting discussions about this, in which an applicant was about to be put aside because he lacked top publications, when a panellist said: 'But this is THE journal in this field, so it won't get any better than this."' (male, SSH)

In general the panel agrees with and follows the opinion of the field expert(s) within the panel. Lamont (2009) described this as adhering to the rule of 'deferring to expertise'. Experts generally have affinity with the topic, which can make them put extra effort in convincing the other panellists of the strengths of that application. But their knowledge can make them more critical too, identifying more easily the weaknesses of applications. Panellists are also found to be quicker enthused by topics they do not know much about. Some fields of research seem to be more attractive for non-experts, because topics are more appealing. In these situations the experts sometimes consider it their task to temper this enthusiasm, by e.g. explaining flaws in the research design.

"Compared to earth sciences people are generally easily enthused [about life sciences]. So often I say 'well, this is not that interesting' instead of 'why don't you understand that this is very interesting?' But yeah, this certainly does not hold for earth sciences. They often had to convince us that it was very interesting. Those times I didn't see this." (male, NTS)

With regard to top talents, the majority of the respondents indicated the entire panel easily recognized them and not much discussion is needed to determine the top three. ${ }^{4}$ Also the least

4 This could not be confirmed in an earlier study on talent selection in grant panels (Van den Besselaar \& Van Arensbergen, 2013). In most panels no clear top could be discerned based on panel review scores, especially not in the beginning of the selection process. 
impressive applicants are said to be easily identified. Most deliberation time is spent on the large middle area in between. Quality differences within this group are very small, leading to a rather arbitrary boundary between just selected and just rejected applicants (see Van Arensbergen \& Van den Besselaar, 2012).

"Actually only the top 2 is evident. Of numbers 3, 4, 5 and so on, I have the feeling of, yeah, it could have been otherwise. It is all being exactly calculated. You have to assign scores including decimals. This gives a kind of impression of quasi exactness, but it isn't." (female, SSH)

The average scores within this group are almost the same, but applicants generally vary on different criteria. One may have a better track record, but less international experience, or one gave a more convincing presentation but has a less innovative research proposal. Therefore it is very important which criteria the panellists emphasize during the discussion. This is found to be dependent on various factors, like panel composition and the comments made by the first speaker (see also Lamont, 2009; Langfeldt, 2002; Luukkonen, 2012). The composition determines the available expertise, but also more subjectively the affinity with the research topic or methods within the panel. What the first speaker starts the discussion with, is also found to be decisive according to the respondents. The strong or weak points of the applicant mentioned first, are strongly supported by other panellists.

"So when someone is assessed, what the first reviewer states will set the tone. When he completely tears down the proposal, the rest is only damage control. When he praises it with arguments, they others will say, yes this is also a way to look at it, and they will immediately consider it as something positive." (male, interdisciplinary)

Furthermore, personal preferences and the atmosphere within the panel are found to influence final selection decisions too. Although panellists are convinced that in the end the top talents are granted, they indicate to have doubts about part of the allocation decisions. Since the quality differences are small, and random (social) factors influence decisions related to the middle group, many rejected applicants could have received grants as well. Most respondents indicate they are aware that this is inherent to the review process, and they would not know how to change this. As the process of grant allocation is conducted by human beings and involves social interaction, these subjective factors can never be fully excluded (Lamont, 2009).

\subsubsection{Talent and gender}

In the interviews we deliberately did not ask explicitly for gender differences, both with regard to panellists as to applicants. As gender in general is quite a sensitive and highly debated topic, we wanted to see if respondents would bring up the gender issue by themselves. The large majority did not. Only a few times, (mostly female) respondents mentioned gender differences explicitly as in female candidates being more introvert and emotional, males being more rational and self-confident. All other references to gender were made to emphasize that gender was not an issue within the panel. Interestingly, these all came from female respondents. Women seem to be more conscious of the gender issue than men, as the following quote also shows: 
I: "Okay, I asked all my questions. Is there anything you would like to add?"

$R$ : Yes, there is one thing I was really wondering whether you would ask me about. Namely to what extent gender plays a role in this whole process. Just briefly, in my mind it is a point of attention. I mean, it is something I'm very attentive to. Myself. So I mean, if things would happen of which I think, well this is not acceptable, then that would be problematic for me. But I have to say, I'm pleasantly surprised." (female, SSH)

The only difference we found between male and female respondents is that in describing top talents, both as grant applicants and as general university employees, women ascribe an higher value to individual capital.

\subsection{Conclusions and implications}

Analyzing talent in terms of symbolic capital, this study contributes to previous research on talent assessment or evaluation practices in several ways. Firstly, it showed the dynamics of evaluation criteria in various phases of the grant allocation process, not only with regard to the final outcomes. We described how criteria relating to various types of capital and the weight assigned to them, change during the review process. Secondly, we showed the differences between what characteristics count as talent when (early career) researchers are selected by grant panels, and the more general notion of talent used by (senior) scholars.

To start with the second issue, the general description of academic talent reflects the various activities scholars are involved in, and it entails a broad variety of skills and traits, combining professional, social and predominantly individual capital. Within the concrete context of grant allocation, a much narrower definition of talent is used and selection is mainly based on professional capital. Counts of publications, awards, grants and international experience are key criteria used in the selection process, especially in the first phase. Only later in the procedure individual capital is added. Being highly productive is obviously an important part of the academic habitus. And, more specifically, in case of early career grants as discussed in this paper, being highly productive can be considered an importance entrance criterion.

As grants are distributed with specific aims - e.g. to do innovative research - it is not surprising that the notion of talent differs between this concrete and the more general forms of talent identification. However, it is important to create a better understanding of talent selection in grant panels, because of the considerable significance assigned to grants. Grants, more specifically the personal career grants, provide academics not only with financial resources to conduct research, but also with academic prestige and further career opportunities. The acquirement of career grants like those of the Dutch Innovational Research Incentives Scheme, is considered an important indicator of talent. Competition for these grants is strong, and having succeeded in obtaining one is seen as proof that the grantee belongs to the top talents. Actually, being in the top $10 \%$ talents in one's field is one of the formal evaluation criteria. Many respondents indicated the only possibility they saw for their talents to stay in academia was by obtaining external grants. Within recruitment, evaluation and promotion procedures, acquirement of external funding - and especially prestigious career grants - form an important criterion. Skills and dispositions needed to acquire grants have been included in the academic habitus. 
When obtaining prestigious career grants becomes leading in recruitment, the tension with the more general notion of talent becomes important. There is the risk of de facto undervaluation of other aspects of individual and social capital, needed for core tasks of university staff as teaching, management and valorization. The growing importance of research grants could also have negative consequences for risky and creative research, as review procedures adopted by funding agencies for allocating grants tend to contain a conservative bias. As evaluations are constrained by the boundaries of current knowledge and reviewers generally highly value criteria like validity, plausibility and a strong publication record, researchers who move to a new field or who have 'wild' ideas, have less chance being funded (Heinze, Shapira, Rogers et al., 2009; Luukkonen, 2012). The question remains whether these 'other' skills are increasingly neglected, or whether these come up in the later part of e.g., grant selection processes. This brings us to the issue of changing characteristics of what counts as talent in grant selection procedures.

In the second part of our study, we studied the various stages of panel reviewing and deliberation, following up on research by Lamont (2009), Langfeldt (2002) and Luukkonen (2012). Talent proved to be assessed differently across the various phases of the selection process, and panels change the way they discuss applications and reach agreement. Within every phase there is an overall agreement on which skills and traits applicants need to have. However, panellists face two main difficulties: first, the broadness of the set of applications they have to review and second, the minimal quality differences within the main group of applicants. Because of the broadness of the applications under review, panels have to cover a wide area of research. Therefore, panellists can only be experts to some of the applications, making the panel usually a 'panel of generalists' (Luukkonen, 2012). Discussions about individual applications are dominated by the few 'real' experts, but all panellists are involved in evaluating the applications and in decision making. In cases where the expert panellists evaluate applications highly positively, these scores will be averaged with the other scores of panellists maybe less familiar with the specific research area, methods or subject. Consequently, high potentials which are not recognized as such by the majority within the panel will end up in the so-called grey area, in which average quality scores hardly vary - even if the experts did recognize them as high potentials.

The second difficulty panellists face is that within the large set of applicants, no clear differentiation can be made using the most common criteria (e.g. publications, grants, international experience). This is often clear in the final scores, which hardly differ between many of the applicants. This implies that other criteria are involved - explicitly or implicitly. These criteria cannot always be fully articulated, as they are often more subjective and related to the tacit dimension of evaluation (Bourdieu, 2004; Van den Brink, 2009). As grant decision making is a social process involving human interactions, subjectivity and random factors can never completely be excluded, they are inherent to the evaluation process. "Judging academic excellence is a process shaped by real-world constraints" (Lamont, 2009: p.155). We showed how panel outcomes are influenced by individuals' behavior (e.g. personal preferences), context specific characteristics (e.g. time restrictions) and group dynamics (e.g. influence opening statement). Panel decisions convert minor differences in quality into enlarged differences in recognition.

Due to these difficulties, many panellists indicate to question the final allocation decisions. Even though they are convinced the top talents are amongst the grantees, a large share of the 
grantees are considered not to be any better than many of the rejected applicants. Many panellists indicate that decisions with regard to this share are liable to arbitrary factors and are partly a matter of luck. Consequently, one would expect a devaluation of the symbolic value of these grants. Paradoxically, despite acknowledging this level of subjectivity and arbitrariness, experienced researchers still ascribe high symbolic value to these grants.

Further research is needed to determine the actual value of these grants for early career researchers. Following up on studies by Bloch et al. (2014), Gerritsen et al. (2013) and Laudel and Gläser (2012), it is necessary to better understand if and how these grants enhance academic careers and moreover, if these researchers are more successful than those without such grants.

Observational studies adding to the interesting work of Lamont (2009) and Langfeldt (2002) would create opportunities to further identify the exact review criteria, including the more tacit criteria, used within panels and the effects of group dynamics on the outcomes of panel review processes. By making these implicit criteria explicit, one may be able to avoid that applicants are assessed on different criteria, and may reduce the influence of subjectivity and random factors when selecting among applicants with almost equally good publication records. And, to what extent do these implicit criteria cover the dimensions of the more general concept of talent that resulted from this study?

\subsection{References}

Baron-Cohen, S. (1998) 'Superiority on the embedded figures test in autism and in normal males: evidence of an "innate talent"?' Behavioral and Brain Sciences, 21(3), 408-409.

Bleijenbergh, I., Benschop, Y. \& Vennix, J. (2013). Group Model Building to support gender equality change in. Achterbergh, J., Benschop, Y., Hendriks, P. \& Van de Ven, A. (Eds.): Op zoek naar het andere: een liber amicorum voor Hans Doorewaard. Boom: Meppel: 80-96.

Bloch, C., Graversen, E. K. \& Pedersen, H. S. (2014). Competitive research grants and their impact on career performance. Minerva, 52, 77-96.

Bourdieu, P. (1986). The forms of capital. In J. Richardson (Ed.) Handbook of Theory and Research for the Sociology of Education (Vol. 1st edition, p 241-258). New York: Greenwood.

Bourdieu, P. (1988). Homo Academicus. Stanford: Stanford University Press.

Bourdieu, P. (2004). Science of science and reflexivity. Cambridge: The University of Chicago and Polity Press.

Brass, D. J., Joseph, G., Greve, H. R., \& Tsai, W. P. (2004). Taking stock of networks and organizations. Academy of Management Journal, 47(6), 795-817.

De Boer, H. \& Jongbloed, B. (2010). Analyse van universitaire jaarverslagen 2009. Achtergrondstudie voor Rathenau Instituut. Enschede: CHEPS.

De Jonge Akademie (2010). Rendement van talent. Aanbevelingen voor motiverend en stimulerend loopbaanbeleid. Amsterdam: De Jonge Akademie.

Gerritsen, S., Plug, E., \& Van der Wiel, K. (2013). Up or out? How individual research grants affect academic careers in the Netherlands (No. 249). Den Haag: CPB Netherlands Bureau for Economic Policy Analysis.

Heinze, T., Shapira, P., Rogers, J.D. \& Senker, J.M. (2009). Organizational and institutional influences on creativity in scientific research. Research Policy, 38, 610-623.

Howe, M.J.A., Davidson, J.W. \& Sloboda, J.A. (1998) 'Innate talents: reality or myth?'. Behavioral and Brain Sciences, 21(3), 399-407. 
Lamont, M. (2009). How professors think. Inside the curious world of academic judgment. Cambridge: Harvard University Press.

Langfeldt, L. (2002). Decision-making in expert panels evaluating research. Constraints, processes and bias. Norwegian Institute for Studies in Innovation, Research and Education, Oslo.

Laudel, G. \& Gläser, J. (2012). The ERC's impact on the grantees' research and their careers. EURECIA Understanding \& Assessing the impact \& Outcomes of the ERC Funding Schemes. Work package 4 summary report. http://www.eurecia-erc.org/wp-content/ uploads/EURECIA-ImpactOnResearchContentAndCareers-SummaryReport.pdf.

Lepori, B, Van den Besselaar, P., Dinges, M., Poti’, B., Reale, E., Slipersaeter, S., Theves, J. \& Van der Meulen, B. (2007). Indicators for comparative analysis of public project funding. Concepts, implementation and evaluation. Research Evaluation, 16(4), 243-255.

Luukkonen, T. (2012). Conservatism and risk-taking in peer review: emerging ERC practices. Research Evaluation, 21, 48-60.

Merton, R. (1968). The Matthew Effect in Science: The reward and communication systems of science are considered. Science, 159(3810), 56-63.

Neufeld, J., Huber, N. \& Wegner, A. (2013). Peer review-based selection decision in individual research funding, applicants' publication strategies and performance: The case of the ERC Starting Grants. Research Evaluation, 22(4), 1-11.

Olbrecht, M. \& Bornmann, L. (2010). 'Panel peer review of grant applications: what do we know from research in social psychology on judgment and decision-making in groups?'. Research Evaluation, 19(4), 293-304.

Thomas, D. \& Nedeva, M. (2012). Characterizing researchers to study research funding agency impacts: the case of European Research Council's Starting Grants. Research Evaluation, 21, 257-269.

Thunnissen, M., Fruytier, B. \& Van den Brink, M. (2010). Beleid en beleving. Onderzoek naar jongetalentenbeleid op Nederlandse universiteiten. Den Haag: SoFoKleS.

Van Arensbergen, P., Van der Weijden, I. \& Van den Besselaar, P. (forthcoming). The selection of talent as a group process. A literature review on the social dynamics of decision-making in grant panels. Research Evaluation.

Van Arensbergen, P. \& Van den Besselaar, P. (2012). The selection of scientific talent in the allocation of research grants. Higher Education Policy, 25, 381-405.

Van Arensbergen, P., Hessels, L.K. \& Van der Meulen, B. (2013). Talent Centraal. Ontwikkeling en selectie van wetenschappers in Nederland. Den Haag: Rathenau Instituut.

Van den Besselaar, P., Sandström, U. \& Van der Weijden, I. (2012). The independence indicator. E. Archambault, Y. Gingras, V. Lariviere (eds.) Science \& Technology Indicators 2012. Montreal: OST \& Science Metrix, 131-141.

Van den Besselaar, P. \& Van Arensbergen, P. (2013). Talent selection and funding of research. Higher Education Policy, 26, 421-427.

Van den Brink, M. (2009). Behind the scenes of science. Gender practices in the recruitment and selection of professors in the Netherlands. PhD thesis, Radboud Universiteit Nijmegen.

Van den Brink, M., Fruytier, B. \& Thunnissen, M. (2012), Talent management in academia: performance systems and HRM policies. Human Resource Management Journal, 23(2), 180-195.

Waring, M. (2013). All in this together? HRM and the individualisation of the academic worker. Higher Education Policy, 26, 397-419. 